\title{
(I, j) - Rw Closed Sets in Bitopological Spaces
}

\author{
M. Karpagadevi \\ Assistant Professor \\ Department of Mathematics \\ Karpagam College of Engineering \\ Coimbatore
}

\author{
A. Pushpalatha \\ Assistant Professor \\ Department of Mathematics \\ Government Arts College \\ Udumalpet
}

\begin{abstract}
In this paper we introduce and study the concept of a new class of closed set called (i, j)-regular weakly closed set (briefly (i,j) - rw closed set) in bitopological spaces and discuss some of their properties in bitopological spaces.
\end{abstract}

\section{Keywords}

(i, j) - rw closed sets

\section{INTRODUCTION}

A triple $(X, \tau 1, \tau 2)$ where $X$ is a non-empty set and $\tau 1$ and $\tau 2$ are topologies on $\mathrm{X}$ is called a bitopological space. Kelly [16] initiated the study of such spaces. In 1985, Fukutake [11] introduced the concepts of $\mathrm{g}$ - closed sets in bitopological spaces and after that several authors turned their attention towards generalizations of various concepts of topology by considering bitopological spaces. S.S. Benchalli and R.S Wali [6] introduced new class of sets called regular weakly - closed (briefly rw - closed) sets in topological spaces which lies between the class of all $\mathrm{w}$ - closed sets and the class of all regular $\mathrm{g}$ - closed sets.

\section{PRELIMINARIES}

In this section we recollect the following basic definitions which are used in this paper.

Definition 2.1: A subset A of a topological space $(\mathrm{X}, \tau)$ is called
i) regular closed [29] if $\mathrm{A}=\mathrm{cl}[\operatorname{int}(\mathrm{A})]$
ii) $\quad$ pre-closed [22] if $\mathrm{cl}[(\operatorname{int}(\mathrm{A})] \subseteq \mathrm{A}$
iii) $\quad$ semiclosed [9] if int $[(\mathrm{cl}(\mathrm{A})] \subseteq \mathrm{A}$
iv) $\quad \alpha$-closed [21] if $\operatorname{cl}[\operatorname{int}(\operatorname{cl}(\mathrm{A}))] \subseteq \mathrm{A}$
v) Semi - pre open [2] $(=\beta$ - open [1]) if $\mathrm{A} \subseteq \mathrm{cl}$ $(\operatorname{int}(\mathrm{cl}(\mathrm{A})))$ and semi- pre-closed $[2](=\beta$ - closed [1]) if int [cl(int (A)) $\subseteq \mathrm{A}$
vi) Semi - generalized closed [7] (briefly sg - closed) if $\operatorname{scl}(\mathrm{A})) \subseteq \mathrm{U}$ whenever $\mathrm{A} \subseteq \mathrm{U}$ and $\mathrm{U}$ is semi open in $X$.
vii) Generalized $\alpha$-closed [18 (briefly g $\alpha$ - closed) if $\alpha \mathrm{cl}(\mathrm{A}) \subseteq \mathrm{U}$ whenever $\mathrm{A} \subseteq \mathrm{U}$ and $\mathrm{U}$ is $\alpha$ open in $\mathrm{X}$.
viii) $\quad \alpha$ - generalized closed [19] (briefly $\alpha$ g - closed) if $\alpha \mathrm{cl}(\mathrm{A}) \subseteq \mathrm{U}$ whenever $\mathrm{A} \subseteq \mathrm{U}$ and $\mathrm{U}$ is open in $\mathrm{X}$.
ix) Generalized pre-closed [20] (briefly gp - closed) if $\mathrm{Pcl}(\mathrm{A}) \subseteq \mathrm{U}$ whenever $\mathrm{A} \subseteq \mathrm{U}$ and $\mathrm{U}$ is open in $\mathrm{X}$.
$\mathrm{x}$ Strongly generalized closed [30] (briefly g*- closed [32]) if $\operatorname{cl}(\mathrm{A})) \subseteq \mathrm{U}$ whenever $\mathrm{A} \subseteq \mathrm{U}$ and $\mathrm{U}$ is $\mathrm{g}$ - open in $\mathrm{X}$.

xi) Mildly generalized closed [24] (briefly mildly $\mathrm{g}$ - closed) if $\operatorname{cl}(\operatorname{int}(\mathrm{A})) \subseteq \mathrm{U}$ whenever $\mathrm{A} \subseteq \mathrm{U}$ and $\mathrm{U}$ is $\mathrm{g}$ - open in $\mathrm{X}$.

xii) Regular weakly generalized closed [23] (briefly rwg - closed) if $\operatorname{cl}(\operatorname{int}(\mathrm{A})) \subseteq \mathrm{U}$ whenever $\mathrm{A} \subseteq \mathrm{U}$ and $\mathrm{U}$ is regular open in $\mathrm{X}$.

Notation: The following notation is used in this paper.

$(i, j)$ denotes the pair of topologies $(\tau i, \tau j)$

Definition 2.2: A subset $A$ of a bitopological space $\left(X, \tau_{1}, \tau_{2}\right)$ is called

i) $\quad(i, j)$-regular open $[8]$ if $\mathrm{A}=$

i Int [jcl(A)]

ii) $\quad(i, j)-p r e-$ open [14] if $A \subset i \operatorname{Int}[j c l(A)]$

iii) $\quad(i, j)-\operatorname{semi}$ open [17] if $A \subset j \mathrm{cl}[\mathrm{i} \operatorname{Int}(\mathrm{A})]$

iv) $\quad(i, j)-\alpha$-open [15] if $A \subset i \operatorname{Int}[j \operatorname{cl}[i \operatorname{Int}(A)]]$

v) $\quad(\mathrm{i}, \mathrm{j})-\mathrm{g}-\operatorname{closed}[11]$ if $\tau_{\mathrm{j}}-\operatorname{cl}(\mathrm{A}) \subseteq \mathrm{U}$ whenever $\mathrm{A} \subseteq \mathrm{U}$ and $\mathrm{U}$ is open in $\tau_{\mathrm{i}}$

vi) $\quad$ vi ) (i, j) - w - closed [13] if $\tau_{\mathrm{j}}-\mathrm{cl}(\mathrm{A}) \subseteq \mathrm{U}$ whenever $\mathrm{A} \subseteq \mathrm{U}$ and $\mathrm{U}$ is semi open in $\tau_{\mathrm{i}}$

vii) $\quad(\mathrm{i}, \mathrm{j})-\mathrm{wg}-\operatorname{closed}[12]$ if $\tau_{\mathrm{j}}-\mathrm{cl}\left[\tau_{\mathrm{j}}\right.$ int $\left.(\mathrm{A})\right] \subseteq \mathrm{U}$ whenever $\mathrm{A} \subseteq \mathrm{U}$ and $\mathrm{U} \in \tau_{\mathrm{i}}$

viii) $\quad(\mathrm{i}, \mathrm{j})-\mathrm{rg}-\operatorname{closed}[3]$ if $\tau_{\mathrm{j}}-\mathrm{cl}(\mathrm{A}) \subseteq \mathrm{U}$ whenever $\mathrm{A} \subseteq \mathrm{U}$ and $\mathrm{U}$ is regular open in $\tau_{\mathrm{i}}$

ix) $\quad(i, j)-g p r-c l o s e d ~[13]$ if $\tau_{j}-\operatorname{pcl}(A) \subseteq U$ whenever $\mathrm{A} \subseteq \mathrm{U}$ and $\mathrm{U}$ is regular open in $\tau_{\mathrm{i}}$

x) $\quad(i, j)-g$ s- closed [10] if $\tau_{j}-\operatorname{scl}(A) \subseteq U$ whenever $\mathrm{A} \subseteq \mathrm{U}$ and $\mathrm{U} \in \tau_{\mathrm{i}}$

xi) (i, j) $-\mathrm{g} *_{-}$closed [28] if $\tau_{\mathrm{j}}-\operatorname{cl}(\mathrm{A}) \subseteq \mathrm{U}$ whenever $\mathrm{A} \subseteq \mathrm{U}$ and $\mathrm{U}$ is $\tau_{\mathrm{i}}$-g-open

xii) $\quad(\mathrm{i}, \mathrm{j})-\mathrm{g} * \mathrm{p}$ - closed [31] if $\tau_{\mathrm{j}}-\operatorname{pcl}(\mathrm{A}) \subseteq \mathrm{U}$ whenever $\mathrm{A} \subseteq \mathrm{U}$ and $\mathrm{U}$ is $\tau_{\mathrm{i}}$-g-open

\section{3. (i,j) - RW CLOSED SETS IN BITOPOLOGICAL SPACES}

In this section, we have introduced a new class of closed sets in bitopological spaces.

Definition 3.1: A subset A of a bitopological space $\left(X, \tau_{1}, \tau_{2}\right)$ is called (i, j) - rw closed if $\tau_{\mathrm{j}}-\operatorname{cl}(\mathrm{A}) \subseteq \mathrm{U}$, whenever $\mathrm{A} \subseteq \mathrm{U}$ and $\mathrm{U}$ is regular semiopen in $\tau_{\mathrm{i}}$.

Theorem 3.2: Every $\tau_{j}$ - closed set in $\left(X, \tau_{i}, \tau_{j}\right)$ is $(i, j)$ - rw closed but not conversely.

Proof: Assume that $A$ is $\tau_{j}$ - closed, $A \subseteq U$ and $U$ is regular semiopen in $\tau_{\mathrm{i}}$. Since $\mathrm{A}$ is $\tau_{\mathrm{j}}$ - closed,

$\operatorname{cl}(\mathrm{A})=\mathrm{A}$. Therefore $\tau_{\mathrm{j}}-\operatorname{cl}(\mathrm{A}) \subseteq \mathrm{U}$. Hence $\mathrm{A}$ is $(\mathrm{i}, \mathrm{j})-$ rw closed. 
Remark 3.3: The converse of the above theorem need not be true as seen from the following example.

Example 3.4 : Let $X=\{a, b, c, d\}$ be a bitopological space with topologies $\tau_{1}=\{\mathrm{X}, \phi,\{\mathrm{a}\},\{\mathrm{a}, \mathrm{b}\},\{\mathrm{b}\},\{\mathrm{a}, \mathrm{b}, \mathrm{c}\}\}$ and $\tau_{2}=$ $\{X, \phi,\{a\},\{b\},\{a, b\}\}$. Then the set $\{a, b\}$ is $(1,2)-r w$ closed but not $\tau_{2}$ - closed.

Theorem 3.5: Every $(i, j)-w$ closed set in $\left(X, \tau_{i}, \tau_{j}\right)$ is $(i, j)$ - rw closed but not conversely.

Proof: Assume that $A$ is $(i, j)-w$ closed,$A \subseteq U$ and $U$ is regular semiopen in $\tau_{\mathrm{i}}$.

Since every $\tau_{\mathrm{i}}$ - regular semiopen is $\tau_{\mathrm{i}}$ - semiopen, $\mathrm{U}$ is regular semiopen in $\tau_{\mathrm{i}}$.

Hence $A$ is $(i, j)$ - rw closed.

Remark 3.6: The converse of the above theorem need not be true as seen from the following example.

Example 3.7 : Let $X=\{a, b, c, d\}$ be a bitopological space with topologies

$\tau_{1}=\{X, \phi,\{a\},\{a, b\},\{b\},\{a, b, c\}\}$ and

$\tau_{2}=\{X, \phi,\{a\},\{b\},\{a, b\}\}$. Then the set $\{a, b\}$ is

$(1,2)$ - rw closed but not $(1,2)$ - w closed.

Theorem 3.8: Every $(i, j)$ - rw closed set in $\left(X, \tau_{i}, \tau_{j}\right)$ is $(i, j)$ - regular generalized closed but not conversely.

Proof: Assume that $A$ is $(i, j)$ - rw closed,$A \subseteq U$ and $U$ is regular open in $\tau_{\mathrm{i}}$.

Since every $\tau_{i}$ - regular open is $\tau_{i}$ - regular semiopen, $U$ is regular semiopen in $\tau_{i}$.

Hence $A$ is $(i, j)$ - regular generalized closed.

Remark 3.9: The converse of the above theorem need not be true as seen from the following example.

Example 3.10 : Let $X=\{a, b, c, d\}$ be a bitopological space with topologies $\tau_{1}=\{\mathrm{X}, \phi,\{\mathrm{a}\},\{\mathrm{a}, \mathrm{b}\},\{\mathrm{b}\},\{\mathrm{a}, \mathrm{b}, \mathrm{c}\}\}$ and $\tau_{2}=$ $\{\mathrm{X}, \phi,\{\mathrm{a}\},\{\mathrm{b}\},\{\mathrm{a}, \mathrm{b}\}\}$. Then the set $\{\mathrm{c}\}$ is $(1,2)-\operatorname{rg}$ closed but not $(1,2)$ - w closed.

Theorem 3.11: Every $(i, j)$ - regular closed set in $\left(\mathrm{X}, \tau_{\mathrm{i}}, \tau_{\mathrm{j}}\right)$ is $(\mathrm{i}, \mathrm{j})$ - rw closed but not conversely.

Proof: The proof follows fromTheorem 3.2

Remark 3.12: The converse of the above theorem need not be true as seen from the following example.

Example 3.13 : Let $X=\{a, b, c, d\}$ be a bitopological space with topologies

$\tau_{1}=\{\mathrm{X}, \phi,\{\mathrm{a}\},\{\mathrm{a}, \mathrm{b}\},\{\mathrm{b}\},\{\mathrm{a}, \mathrm{b}, \mathrm{c}\}\}$ and

$\tau_{2}=\{X, \phi,\{a\},\{b\},\{a, b\}\}$. Then the set $\{a, b\}$ is

$(1,2)$ - rw closed but not $(1,2)$ - regular closed.

Theorem 3.14: Every $(i, j)$ - rw closed set in

$\left(X, \tau_{i}, \tau_{j}\right)$ is $(i, j)$ - gpr closed but not conversely.

Proof: Assume that A is $(i, j)-r w$ closed,$A \subseteq U$ and $U$ is regular open in $\tau_{i}$.

Since every $\tau_{\mathrm{i}}$ - regular open is $\tau_{\mathrm{i}}$ - regular semiopen and (i,j) rw closed,

$(\mathrm{i}, \mathrm{j})-\operatorname{pcl}(\mathrm{A}) \subseteq \tau_{\mathrm{j}}-\operatorname{cl}(\mathrm{A}) \subseteq \mathrm{U}$. Therefore $(\mathrm{i}, \mathrm{j})-\operatorname{pcl}(\mathrm{A}) \subseteq$ $U$. Hence $A$ is

(i, j) - gpr closed.
Remark 3.15: The converse of the above theorem need not be true as seen from the following example.

Example 3.16 : Let $X=\{a, b, c, d\}$ be a bitopological space with topologies

$\tau_{1}=\{\mathrm{X}, \phi,\{\mathrm{a}\},\{\mathrm{a}, \mathrm{b}\},\{\mathrm{b}\},\{\mathrm{a}, \mathrm{b}, \mathrm{c}\}\}$ and $\tau_{2}=\{\mathrm{X}, \phi,\{\mathrm{c}\},\{\mathrm{b}\}$, $\{c, b\}\}$. Then the set $\{a\}$ is

$(1,2)$ - gpr closed but not $(1,2)$ - rw closed.

Remark 3.17: The following example shows that $(1,2)$ - rw closed set is independent of $(1,2)-\mathrm{g}^{*}$ - closed set.

Example 3.18 : Let $X=\{a, b, c, d\}$ be a bitopological space with topologies

$\tau_{1}=\{\mathrm{X}, \phi,\{\mathrm{a}\},\{\mathrm{a}, \mathrm{b}\},\{\mathrm{b}\},\{\mathrm{a}, \mathrm{b}, \mathrm{c}\}\}$ and $\tau_{2}=\{\mathrm{X}, \phi,\{\mathrm{a}\},\{\mathrm{b}\}$, $\{a, b\}\}$. Then the set $\{d\}$ is

$(1,2)-\mathrm{g}^{*}$ - closed but not $(1,2)$ - rw closed and $\{\mathrm{a}, \mathrm{b}\}$ is $(1$, 2) - rw closed but not

$(1,2)-\mathrm{g}^{*}$ - closed.

Remark 3.19: The following example shows that $(1,2)$ - rw closed set is independent of $(1,2)$ - $\mathrm{g}$ - closed set.

Example 3.20 : Let $X=\{a, b, c, d\}$ be a bitopological space with topologies

$\tau_{1}=\{\mathrm{X}, \phi,\{\mathrm{a}\},\{\mathrm{a}, \mathrm{b}\},\{\mathrm{b}\},\{\mathrm{a}, \mathrm{b}, \mathrm{c}\}\}$ and $\tau_{2}=\{\mathrm{X}, \phi,\{\mathrm{a}\},\{\mathrm{b}\}$, $\{a, b\}\}$. Then the set $\{d\}$ is

$(1,2)$ - $g$-closed but not $(1,2)$ - rw closed and $\{a, b\}$ is $(1,2)$ - rw closed but not

$(1,2)$ - $\mathrm{g}$ - closed.

Remark 3.21: The following example shows that $(1,2)$ - rw closed set is independent of $(1,2)$ - wg - closed set.

Example 3.22 : Let $X=\{a, b, c, d\}$ be a bitopological space with topologies

$\tau_{1}=\{X, \phi,\{a\},\{a, b\},\{b\},\{a, b, c\}\}$ and $\tau_{2}=\{X, \phi,\{a\},\{b\}$, $\{a, b\}\}$. Then the set $\{d\}$ is

$(1,2)$ - wg - closed but not $(1,2)$ - rw closed and

$\{\mathrm{a}, \mathrm{b}\}$ is $(1,2)-\mathrm{rw}$ closed but not

$(1,2)$ - wg - closed.

Remark 3.23: The following example shows that $(1,2)$ - rw closed set is independent of $(1,2)$ - semiclosed set.

Example 3.24 : Let $X=\{a, b, c, d\}$ be a bitopological space with topologies

$\tau_{1}=\{X, \phi,\{a\},\{a, b\},\{b\},\{a, b, c\}\}$ and $\tau_{2}=\{X, \phi,\{a\},\{b\}$, $\{a, b\}\}$. Then the set $\{d\}$ is

$(1,2)$ - semiclosed but not $(1,2)$ - rw closed and $\{a, b\}$ is (1,

2) - rw closed but not

$(1,2)$ - semiclosed.

Remark 3.25: The following example shows that $(1,2)$ - rw closed set is independent of $(1,2)$ - $\alpha$ closed set.

Example 3.26 : Let $X=\{a, b, c, d\}$ be a bitopological space with topologies

$\tau_{1}=\{\mathrm{X}, \phi,\{\mathrm{a}\},\{\mathrm{a}, \mathrm{b}\},\{\mathrm{b}\},\{\mathrm{a}, \mathrm{b}, \mathrm{c}\}\}$ and $\tau_{2}=\{\mathrm{X}, \phi,\{\mathrm{a}\},\{\mathrm{b}\}$, $\{a, b\}\}$.

Then the set $\{\mathrm{d}\}$ is $(1,2)-\alpha$ closed but not $(1,2)$ - rw closed and $\{a, b\}$ is $(1,2)$ - rw closed but not $(1,2)-\alpha$ closed.

Remark 3.27: The following example shows that $(1,2)$ - rw closed set is independent of $(1,2)$ - g $\alpha$ closed set. 
Example 3.28 : Let $X=\{a, b, c, d\}$ be a bitopological space with topologies

$\tau_{1}=\{\mathrm{X}, \phi,\{\mathrm{a}\},\{\mathrm{a}, \mathrm{b}\},\{\mathrm{b}\},\{\mathrm{a}, \mathrm{b}, \mathrm{c}\}\}$ and $\tau_{2}=\{\mathrm{X}, \phi,\{\mathrm{a}\},\{\mathrm{b}\}$, $\{a, b\}\}$.

Then the set $\{\mathrm{d}\}$ is $(1,2)$ - g $\alpha$ closed but not $(1,2)$ - rw closed and $\{a, b\}$ is $(1,2)$ - rw closed but not

$(1,2)$ - g $\alpha$ closed.

Remark 3.29: The following example shows that $(1,2)$ - rw closed set is independent of $(1,2)-\alpha \mathrm{g}$ closed set.

Example 3.30 : Let $X=\{a, b, c, d\}$ be a bitopological space with topologies

$\tau_{1}=\{\mathrm{X}, \phi,\{\mathrm{a}\},\{\mathrm{a}, \mathrm{b}\},\{\mathrm{b}\},\{\mathrm{a}, \mathrm{b}, \mathrm{c}\}\}$ and $\tau_{2}=\{\mathrm{X}, \phi,\{\mathrm{a}\},\{\mathrm{b}\}$, $\{a, b\}\}$. Then the set $\{d\}$ is

$(1,2)$ - $\alpha$ g closed but not $(1,2)$ - rw closed and $\{a, b\}$ is $(1$,

2) - rw closed but not

$(1,2)-\alpha g$ closed.

Remark 3.31: The following example shows that

$(1,2)$ - rw closed set is independent of $(1,2)$ - sg closed set.

Example 3.32 : Let $X=\{a, b, c, d\}$ be a bitopological space with topologies

$\tau_{1}=\{\mathrm{X}, \phi,\{\mathrm{a}\},\{\mathrm{a}, \mathrm{b}\},\{\mathrm{b}\},\{\mathrm{a}, \mathrm{b}, \mathrm{c}\}\}$ and $\tau_{2}=\{\mathrm{X}, \phi,\{\mathrm{a}\},\{\mathrm{b}\}$, $\{a, b\}\}$. Then the set $\{d\}$ is

$(1,2)$ - sg closed but not $(1,2)$ - rw closed and $\{a, b\}$ is $(1$,

2) - rw closed but not $(1,2)$ - sg closed.

Remark 3.33: The following example shows that $(1,2)$ - rw closed set is independent of $(1,2)$ - gs closed set.

Example 3.34 : Let $X=\{a, b, c, d\}$ be a bitopological space with topologies

$\tau_{1}=\{\mathrm{X}, \phi,\{\mathrm{a}\},\{\mathrm{a}, \mathrm{b}\},\{\mathrm{b}\},\{\mathrm{a}, \mathrm{b}, \mathrm{c}\}\}$ and $\tau_{2}=\{\mathrm{X}, \phi,\{\mathrm{a}\},\{\mathrm{b}\}$, $\{a, b\}\}$. Then the set $\{d\}$ is

$(1,2)$ - gs closed but not $(1,2)$ - rw closed and $\{a, b\}$ is $(1$,

2) - rw closed but not

$(1,2)$ - gs closed.

Remark 3.35: The following example shows that

$(1,2)$ - rw closed set is independent of $(1,2)$ - gsp closed set.

Example 3.36 : Let $X=\{a, b, c, d\}$ be a bitopological space with topologies

$\tau_{1}=\{\mathrm{X}, \phi,\{\mathrm{a}\},\{\mathrm{a}, \mathrm{b}\},\{\mathrm{b}\},\{\mathrm{a}, \mathrm{b}, \mathrm{c}\}\}$ and $\tau_{2}=\{\mathrm{X}, \phi,\{\mathrm{a}\},\{\mathrm{b}\}$, $\{a, b\}\}$. Then the set $\{d\}$ is

$(1,2)$ - gsp closed but not $(1,2)$ - rw closed and $\{a, b\}$ is $(1$,

2) - rw closed but not

$(1,2)$ - gsp closed.

Remark 3.37: The following example shows that $(1,2)$ - rw closed set is independent of $(1,2)-\beta$ closed set.
Example 3.38 : Let $X=\{a, b, c, d\}$ be a bitopological space with topologies

$\tau_{1}=\{X, \phi,\{a\},\{a, b\},\{b\},\{a, b, c\}\}$ and $\tau_{2}=\{X, \phi,\{a\},\{b\}$, $\{a, b\}\}$. Then the set $\{d\}$ is

$(1,2)$ - $\beta$ closed but not $(1,2)$ - rw closed and $\{a, b\}$ is $(1,2)$ rw closed but not

$(1,2)-\beta$ closed.

Remark 3.39: The following example shows that $(1,2)$ - rw closed set is independent of $(1,2)$ - preclosed set.

Example 3.40 : Let $X=\{a, b, c, d\}$ be a bitopological space with topologies

$\tau_{1}=\{\mathrm{X}, \phi,\{\mathrm{a}\},\{\mathrm{a}, \mathrm{b}\},\{\mathrm{b}\},\{\mathrm{a}, \mathrm{b}, \mathrm{c}\}\}$ and $\tau_{2}=\{\mathrm{X}, \phi,\{\mathrm{a}\},\{\mathrm{b}\}$, $\{a, b\}\}$. Then the set $\{d\}$ is

$(1,2)$ - preclosed but not $(1,2)$ - rw closed and

$\{\mathrm{a}, \mathrm{b}\}$ is $(1,2)-\mathrm{rw}$ closed but not

$(1,2)$ - preclosed.

Remark 3.41: The following example shows that $(1,2)$ - rw closed set is independent of $(1,2)$ - gp closed set.

Example 3.42 : Let $X=\{a, b, c, d\}$ be a bitopological space with topologies

$\tau_{1}=\{X, \phi,\{a\},\{a, b\},\{b\},\{a, b, c\}\}$ and $\tau_{2}=\{X, \phi,\{a\},\{b\}$, $\{a, b\}\}$. Then the set $\{d\}$ is

$(1,2)$ - gp closed but not $(1,2)$ - rw closed and $\{a, b\}$ is $(1$,

2) - rw closed but not

$(1,2)$ - gp closed.

Remark 3.43: The following example shows that $(1,2)$ - rw closed set is independent of $(1,2)$ - swg closed set.

Example 3.44 : Let $X=\{a, b, c, d\}$ be a bitopological space with topologies

$\tau_{1}=\{X, \phi,\{a\},\{a, b\},\{b\},\{a, b, c\}\}$ and $\tau_{2}=\{X, \phi,\{a\},\{b\}$, $\{a, b\}\}$. Then the set $\{d\}$ is

$(1,2)$ - swg closed but not $(1,2)$ - rw closed and

$\{\mathrm{a}, \mathrm{b}\}$ is $(1,2)$ - rw closed but not

$(1,2)$ - swg closed.

Remark 3.45: The following example shows that $(1,2)$ - rw closed set is independent of $(1,2)$ - mildly $\mathrm{g}$ closed set.

Example 3.46 : Let $X=\{a, b, c, d\}$ be a bitopological space with topologies $\tau_{1}=\{\mathrm{X}, \phi,\{\mathrm{a}\},\{\mathrm{a}, \mathrm{b}\},\{\mathrm{b}\},\{\mathrm{a}, \mathrm{b}, \mathrm{c}\}\}$ and $\tau_{2}=\{\mathrm{X}, \phi,\{\mathrm{a}\},\{\mathrm{b}\}$, $\{a, b\}\}$. Then the set $\{d\}$ is

$(1,2)$ - mildly g-closed but not $(1,2)$ - rw closed and $\{a, b\}$ is $(1,2)$ - rw closed but not $(1,2)$ - mildly g- closed. 


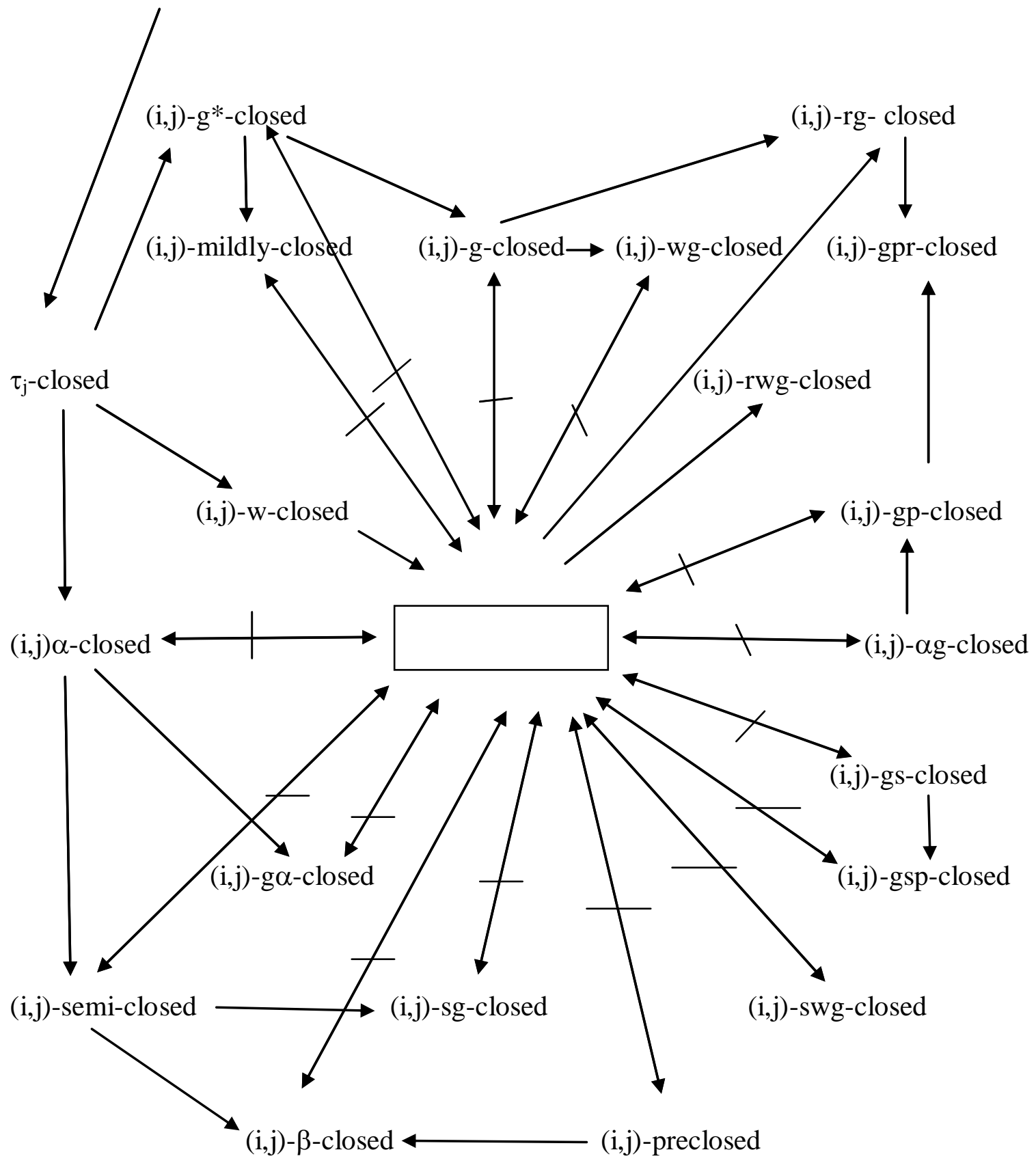

Fig 1: (i,j)-regular -closed

Theorem 3.48: In a bitopological space $\left(X, \tau_{1}, \tau_{2}\right)$ let $A$ and $B$ are $(i, j)$ - rw closed set then $A \cup B$ is $(i, j)$ - rw closed.

Proof: Assume that A and B are (i,j) - rw closed set in $\left(X, \tau_{1}\right.$, $\tau_{2}$ ). Let $\mathrm{U}$ be a regular semiopen in $\tau_{\mathrm{i}}$ such that $\mathrm{A} \cup \mathrm{B} \subseteq \mathrm{U}$.

Then $\mathrm{A} \subseteq \mathrm{U}$ and $\mathrm{B} \subseteq \mathrm{U}$. Since $\mathrm{A}$ and $\mathrm{B}$ are

(i, j) - rw closed, $\tau_{\mathrm{j}}-\operatorname{cl}(\mathrm{A}) \subseteq \mathrm{U}$ and $\tau_{\mathrm{j}}-\operatorname{cl}(\mathrm{B}) \subseteq \mathrm{U}$. Hence $\tau_{\mathrm{j}}$ $\operatorname{cl}(\mathrm{A} \cup \mathrm{B}) \subseteq \tau_{\mathrm{j}}-\operatorname{cl}(\mathrm{A}) \cup$

$\tau_{j}-\operatorname{cl}(B) \subseteq \mathrm{U}$. Therefore $\tau_{\mathrm{j}}-\operatorname{cl}(\mathrm{A} \cup \mathrm{B}) \subseteq \mathrm{U}$. Hence $\mathrm{A} \cup \mathrm{B}$ is (i, j) - rw closed.

Remark 3.49: The following example shows that the intersection of two $(i, j)$ - rw closed sets in $\left(X, \tau_{1}, \tau_{2}\right)$ is generally not an $(i, j)$ - rw closed set.

Example 3.50 : Let $X=\{a, b, c, d\}$ be a bitopological space with topologies

$\tau_{1}=\{X, \phi,\{a\},\{a, b\},\{b\},\{a, b, c\}\}$ and $\tau_{2}=\{X, \phi,\{a\},\{b\}$, $\{a, b\}\}$. If $A=\{a, b\}$ and

$B=\{a, c, d\}$ then $A$ and $B$ are $(1,2)-r w$ closed set in $\left(X, \tau_{1}\right.$, $\left.\tau_{2}\right)$ but $A \cap B=\{a\}$ is not an $(1,2)$ - rw closed set in $\left(X, \tau_{1}\right.$, $\left.\tau_{2}\right)$.

Theorem 3.51 : If a subset $A$ of $\left(X, \tau_{1}, \tau_{2}\right)$ is $(i, j)$ - rw closed set, then $\tau_{\mathrm{j}}$ - cl(A)-A does not contain any non-empty regular semiopen set in $\tau_{\mathrm{i}}$. 
Proof: Suppose that A is (i , j) - rw closed. Let $\mathrm{U}$ be a regular semiopen in $\tau_{\mathrm{i}}$ such that

$\tau_{\mathrm{j}}-\operatorname{cl}(\mathrm{A})-\mathrm{A} \supset \mathrm{U}$ and $\mathrm{U} \neq \phi$. Now $\mathrm{U} \subset \tau_{\mathrm{j}}-\mathrm{cl}(\mathrm{A})-\mathrm{A}, \mathrm{U} \subset \mathrm{X}$ $-\mathrm{A}, \mathrm{X}-\mathrm{U} \supset \mathrm{A}$ which implies $\mathrm{A} \subset \mathrm{X}-\mathrm{U}$. Since $\mathrm{U}$ is regular semiopen in $\tau_{i}, X-U$ is also regular semiopen in $\tau_{i .} B y \tau_{j}-$ $\mathrm{cl}(\mathrm{A}) \subseteq \mathrm{X}-\mathrm{U}, \mathrm{U} \subset \mathrm{X}-\tau_{\mathrm{j}}-\mathrm{cl}(\mathrm{A})$ and $\mathrm{U} \subset \tau_{\mathrm{j}}-\operatorname{cl}(\mathrm{A})$.

Therefore

$\mathrm{U} \subset \tau_{\mathrm{j}}-\mathrm{cl}(\mathrm{A}) \cap\left(\mathrm{X}-\tau_{\mathrm{j}}-\mathrm{cl}(\mathrm{A})\right)=\phi$. Which implies $\mathrm{U}=\phi$ which is a contradiction. Hence $\tau_{j}-\mathrm{cl}(\mathrm{A})-\mathrm{A}$ does not contain any non-empty regular semiopen set in $\tau_{\mathrm{i}}$.

Remark 3.52: The converse of the above theorem need not be true as seen from the following example.

Example 3.53: If $\tau_{j}$ - cl (A) -A contains no non-empty regular semiopen subset in

$\left(\mathrm{X}, \tau_{1}, \tau_{2}\right)$. Then A need not be $(1,2)$ - rw closed. Consider $\mathrm{X}$ $=\{\mathrm{a}, \mathrm{b}, \mathrm{c}, \mathrm{d}\}$ be a bitopological space with topologies $\tau_{1}=\{\mathrm{X}$, $\phi,\{a\},\{a, b\},\{b\},\{a, b, c\}\}$ and $\tau_{2}=\{X, \phi,\{a\},\{b\},\{a, b\}\}$. Let $\mathrm{A}=\{\mathrm{c}\}$. Then $\tau_{\mathrm{j}}-\mathrm{cl}(\mathrm{A})-\mathrm{A}=\{\mathrm{c}, \mathrm{d}\}=\{\mathrm{d}\}$ does not contain any non-empty regular semiopen set but $\mathrm{A}$ is not an $(1,2)$ - rw closed.

Theorem 3.54: For an element $x \in X$ the set $X-\{x\}$ is ( $i, j)$ rw closed or regular semiopen in $\tau_{\mathrm{i}}$.

Proof: Suppose $X-\{x\}$ is not regular semiopen in $\tau_{\mathrm{i}}$, then $X$ is the only regular semi open containing $X-\{x\}$ which implies $\tau_{\mathrm{j}}-\mathrm{cl}[\mathrm{X}-\{\mathrm{x}\}] \subseteq \tau_{\mathrm{j}}-\mathrm{cl}(\mathrm{x})=\mathrm{X}$. Therefore $\tau_{\mathrm{j}}-\mathrm{cl}[\mathrm{X}-\{\mathrm{x}\}] \subseteq \mathrm{X}$. Thus $\mathrm{X}-\{\mathrm{x}\}$ is $(\mathrm{i}, \mathrm{j})$ - rw closed.

Theorem 3.55: If $A$ is an $(i, j)$ - rw closed subset of $\left(X, \tau_{1}, \tau_{2}\right)$ such that

$\mathrm{A} \subset \mathrm{B} \subset \tau_{\mathrm{j}}-\mathrm{cl}(\mathrm{A})$, then $\mathrm{B}$ is a $(\mathrm{i}, \mathrm{j})$ - rw closed set in $\left(\mathrm{X}, \tau_{1}\right.$, $\left.\tau_{2}\right)$.

Proof: Let A be a (i,j) - rw closed set of $X$ such that $A \subset B$ $\subset \tau_{j}-\operatorname{cl}(A)$. Let $B \subseteq U$ and $U$ is regular semiopen in $\tau_{i}$. Then $A \subseteq U$. Since $A$ is $(i, j)-$ rw closed, $\tau_{j}-c l(A) \subseteq U$. Now $\tau_{j}-$ $\operatorname{cl}(B) \subseteq \tau_{j}-\operatorname{cl}\left[\tau_{j}-\operatorname{cl}(A)\right]=\tau_{j}-\operatorname{cl}(A) \subseteq$ U. Therefore $\tau_{j}-\operatorname{cl}$ (B) $\subseteq \overline{\mathrm{U}}$. Hence B is $(\mathrm{i}, \mathrm{j})$ - rw closed.

Remark 3.56: The converse of the above theorem need not be true as seen from the following example.

Example 3.57 : Consider $X=\{a, b, c, d\}$ be a bitopological space with topologies $\tau_{1}=\{X, \phi,\{a\},\{a, b\},\{b\},\{a, b, c\}\}$ and $\tau_{2}=\{X, \phi,\{a\},\{b\},\{a, b\}\}$. Let $A=\{c, d\}$ and $B=\{a, c, d\}$. Then $\mathrm{A}$ and $\mathrm{B}$ are

$(1,2)$ - rw closed but $\mathrm{A} \subseteq \mathrm{B} \not \subset \tau_{\mathrm{j}}-\mathrm{cl}(\mathrm{A})$.

Theorem 3.58: Let A be (i, j) - rw closed. Then A is $\tau_{j}$ closed if and only $\tau_{j}$ - cl (A) $-\mathrm{A}$ is $\tau_{i}$-regular semiopen. Proof: Suppose A is $\tau_{\mathrm{j}}$-closed, then $\tau_{\mathrm{j}}$-cl $(\mathrm{A})=\mathrm{A}$ and $\tau_{\mathrm{j}}$ - cl (A) $-\mathrm{A}=\phi$ which is $\tau_{\mathrm{i}}$ - Regular semiopen.

Converse: Suppose $\tau_{\mathrm{j}}$ - cl (A) $-\mathrm{A}$ is $\tau_{\mathrm{i}}$ - regular semiopen. Since A is $(i, j)$ - rw closed by previous theorem, $\tau_{j}-\operatorname{cl}(A)-$ A does not contain any non-empty $\tau_{\mathrm{i}}$ - regular semiopen set. Then $\tau_{\mathrm{j}}-\mathrm{cl}(\mathrm{A})-\mathrm{A}=\phi$ which implies $\tau_{\mathrm{j}}-\mathrm{cl}(\mathrm{A})=\mathrm{A}$. Hence $\mathrm{A}$ is $\tau_{\mathrm{j}}$ - closed.

Theorem 3.59: If $A$ is $\tau_{j}$ - regular open and (i, j) - rg closed, then $A$ is (i, j) - rw closed.

Proof: Let $\mathrm{U}$ be any $\tau_{\mathrm{i}}$ - regular semiopen such that $\mathrm{A} \subset \mathrm{U}$.

Since A is $\tau_{j}$ - regular open and (i,j) - rg closed we have $\tau_{j}$ - cl
(A) $\subset$ A. Then $\tau_{\mathrm{j}}-\mathrm{cl}(\mathrm{A}) \subset \mathrm{A} \subset \mathrm{U}$. Hence $\tau_{\mathrm{j}}-\mathrm{cl}(\mathrm{A}) \subseteq \mathrm{U}$. Thus A is (i,j) - rw closed.

Theorem 3.60: If a subset A of a bitopological space is both $\tau_{i}$ - regular semi open and

$(\mathrm{i}, \mathrm{j})$ - rw closed, then it is $\tau_{\mathrm{j}}$ - closed.

Proof: Now $A \subset A$. Then $\tau_{j}-\operatorname{cl}(A) \subseteq A, A \subseteq \tau_{j}-\operatorname{cl}(A)$.

Therefore $\tau_{\mathrm{j}}-\mathrm{cl}(\mathrm{A})=\mathrm{A}$.

Hence $A$ is $\tau_{j}$ - closed.

Theorem 3.61: Let A be $\tau_{\mathrm{i}}$ - regular semiopen and $(i, j)$ - rw closed in $\left(X, \tau_{1}, \tau_{2}\right)$. Suppose that $F$ is $\tau_{j}$ - closed in $\left(\mathrm{X}, \tau_{1}, \tau_{2}\right)$, then $\mathrm{A} \cap \mathrm{F}$ is an $(\mathrm{i}, \mathrm{j})$ - rw closed set in $\left(\mathrm{X}, \tau_{1}, \tau_{2}\right)$. Proof: Let A be $\tau_{i}$ - regular semiopen and $(i, j)$ - rw closed in $\left(\mathrm{X}, \tau_{1}, \tau_{2}\right)$ and $\mathrm{F}$ be

$\tau_{j}$ - closed. By previous theorem, $\mathrm{A}$ is $\tau_{\mathrm{j}}$ - closed. So $\mathrm{A} \cap \mathrm{F}$ is $\tau_{j}$-closed and hence $A \cap F$ is an $(i, j)$ - rw closed set in $\left(X, \tau_{1}\right.$, $\left.\tau_{2}\right)$.

Theorem 3.62: If A is both $\tau_{\mathrm{j}}$ - open and (i, j) - g- closed, then it is $(i, j)$ - rw closed.

Proof: Let $A$ be a $\tau_{j}$ - open and (i, j) - g- closed. Let $A \subset U$ and $\mathrm{U}$ is $\tau_{\mathrm{i}}$ - regular semiopen. By hypothesis $\tau_{\mathrm{j}}-\mathrm{cl}(\mathrm{A}) \subseteq \mathrm{A}$ (ie) $\tau_{\mathrm{j}}$ - cl $(\mathrm{A}) \subseteq \mathrm{U}$. Thus A is (i, j) - rw closed.

Remark 3.63: If $A$ is both $\tau_{j}$ - open and $(i, j)$ - rw closed in $\left(\mathrm{X}, \tau_{1}, \tau_{2}\right)$, then A need not be

$(\mathrm{i}, \mathrm{j})$ - $\mathrm{g}$ - closed in general as seen from the following example.

Example 3.64 : Consider $X=\{a, b, c, d\}$ be a bitopological space with topologies $\tau_{1}=\{\mathrm{X}, \phi,\{\mathrm{a}\},\{\mathrm{a}, \mathrm{b}\},\{\mathrm{b}\},\{\mathrm{a}, \mathrm{b}, \mathrm{c}\}\}$ and $\tau_{2}=\{X, \phi,\{a\},\{b\},\{a, b\}\}$. In this bitopological space the subset $\{a, b\}$ is $\tau_{j}$ - open and (i,j) - rw closed, but not $(i, j)$ - gclosed.

Theorem 3.65: If a subset A of a bitopological space is both $\tau_{\mathrm{i}}$ - open and $(\mathrm{i}, \mathrm{j})$ - wg closed, then it is $(\mathrm{i}, \mathrm{j})$ - rw closed. Proof: Suppose a subset A of $X$ is both $\tau_{i}$ - open and (i,j) - wg closed. Let $A \subset U$ with $U$ is $\tau_{i}-$ regular semiopen in $X$. Now $\mathrm{A} \supset \tau_{\mathrm{i}} \mathrm{cl}[\operatorname{int}(\mathrm{A})]=\mathrm{A}$ as $\mathrm{A}$ is $\tau_{\mathrm{i}}$ - open. That is $\tau_{\mathrm{j}}-\mathrm{cl}(\mathrm{A}) \subset \mathrm{A}$ $\subset \mathrm{U}$. Thus $\mathrm{A}$ is an (i,j) - rw closed set in $\mathrm{X}$.

\section{REFERENCES}

[1] Abd El-Monsef .M.E., El-Deeb.S.N and Mahmoud.R.A., $\beta-$ open sets and $\beta-$ continuous mappings, Bul.Fac.Sci.Assisut Univ.12(1983),77-90

[2] Andrijevic.D, Semi-preopen sets,Mat.Vesnik 38(1986),2432

[3] Arockiarani. I, Studies on generalizations of generalized closed sets and maps in topological spaces, Ph.D., Thesis, Bharathiar Univ., Coimbatore,1997.

[4] Arya, S.P and Nour.T.M., Quasi Semi-components in bitopological spaces, Indian J.Pure Appl.Math., 21(1990), 649-652.

[5] Arya, S.P and Nour.T.M., Separation axioms for bitopological spaces, Indian J.Pure Appl.Math., 19(1998), 42-50.

[6] Benchalli.S.S and Wali.R.S., On R $\omega$-closed sets in topological spaces, Bull.Malays.math.Sci.Soc(2) 30(2) (2007), 99-110. 
[7] Bhattacharyya, P. and Lahiri, B.K., Semi-generalized closed sets in topology, Indian J.Math., 29(1987), 376382.

[8] Bose.S., Sinha.D., Almost open, almost closed, Өcontinuous and almost compact mappings in bitopological spaces.Bull.Calcutta Math.Soc.73(1981), 345-354.

[9] Crossley.S.G and Hildebrand.S.K, Semi-closure, Texas J.Sci.22(1971),99-112.

[10] El-Tantawy.O.A and Abu-Donia.H.M, Generalized Separation Axioms in Bitopological Spaces, The Arabian $\Pi$ for Science and Engg.Vol.30,N0.1A,117-129(2005)

[11] Fukutake, T., On generalized closed sets in bitopological spaces, Bull.Fukuoka Univ.Ed.Part III, 35(1986), 19-28.

[12] Futake, T., Sundaram, P., and Nagaveni, N., On weakly generalized closed sets, weakly generalized continuous maps and Twg spaces in bitopological spaces, Bull.Fukuoka Univ.Ed.Part III, 48(1999), 33-40.

[13] Futake, T., Sundaram, P., and SheikJohn.M., 2002, $\omega-$ closed sets, $\omega$-open sets and $\omega$-continuity in bitopological spaces Bull.Fukuoka Univ.Ed.Vol.51.Part III 1-9.

[14] Jelic.M., A decomposition of pairwise continuity, J. Inst.Math.Comp.Sci.,3,25-29(1990).

[15] Jelic.M., Feebly p-continuous mappings.V International Meeting on Topology in Italy (Itaian) (Lecce,1990/Otranto,1990).Rend.Circ.Mat.Palermo(2) Suppl.No.24(1990),387-395.

[16] Kelly, J.C., Bitopological spaces, Proc.London Math.Soc.13(1963), 71-89.

[17] Maheswari, S.N., and Prasad, R., Semi open sets and semi continuous functions in bitopological spaces. Math Notae, 26, (1977/78),29-37.

[18] Maki, H., Devi, R., and Balachandran, K., Associated topologies of generalized $\alpha$-closed sets, mem. Fac. Sci. Kochiuniv.Ser.A.math., 15(1994), 51-63.

[19] Maki, H., Devi, R., and Balachandran, K., generalized $\alpha$ closed sets in topology, Bull. Fukuoka Univ. Ed. Part III, 42 (1993) 13-21.
[20] Maki.H, Umehara.J and Noiri.T, Every Topological space is pre- $\mathrm{T}_{1 / 2} \quad, \quad$ Mem.Fac.Sci.Kochi Univ.Ser.A.Math.17(1996),33-42

[21] Mashhour.A.S., Hasanein.I.A and El-Deeb.S.N., $\alpha-$ open mappings,Acta.Math.Hungar.41(1983),213-218.

[22] Mashhour.A.S., Abd El-Monsef .M.E. and ElDeeb.S.N.On pre continuous mappings and week precontinuous mappings,Proc Math, Phys.Soc.Egypt 53(1982),47-53.

[23] Nagaveni.N., Studies on Generalizations of Homeorphisms in Topological Spaces,Ph.D. Thesis, Bharathiar University, Coimbatore, 1999.

[24] Park, J.K., and Park, J.H., Mildly generalized closed sets, almost normal and miklly. Chaos, Solitons and Fractals 20(2004), 1103-1111.

[25] Patty, C.W., Bitopological spaces, Dukemath.J.34(1967), 387-392.

[26] Pushpalatha, A., Studies on generalizations of mappings in topological spaces, Ph.D., Thesis, Bharathiar University, Coimbatore -2000 .

[27] Rajamani, M. and Viswanathan, K., On ags-closed sets in bitopological spaces, Bull. Pure and applied Sciences. Vol. 24E (No.1) 2005: P.39-53.

[28] SheikJohn, M. and Sundaram, P., g*-closed sets in bitopological spaces, Indian J. Pure. Appl. Math., 35(1), 71-80(2004).

[29] Stone.M., Application of the Theory of Boolean rings to general Topology, Trans.Amer.Math.Soc.41(1937),374481

[30] Sundaram, P. and SheikJohn.M., ON $\omega$-closed sets in topology, Acta ciencia Indica 4(2000), 389-392.

[31] Veerakumar M.K.R.S., g*-preclosed sets in Topology.Acta Ciencia Indica,XXVIII(1):51:60,2002.

[32] Veerakumar M.K.R.S., Between closed sets and gclosed sets, Mem.Fac.Sci.Kochiuniv.(Math).21(2000),119. 